\title{
XXVI. Further observations on the voltaic decomposition of solutions
}

\section{Arthur Connell Esq.}

To cite this article: Arthur Connell Esq. (1844) XXVI. Further observations on the voltaic decomposition of solutions, Philosophical Magazine Series 3, 24:158, 161-165, DOI: 10.1080/14786444408644827

To link to this article: http://dx.doi.org/10.1080/14786444408644827

曲 Published online: 30 Apr 2009.

Submit your article to this journal $₫$

Џll Article views: 2

Q View related articles $₫$ 


\title{
JOURNAL OF SCIENCE.
}

\author{
[THIRD SERIES.]
}

$M A R C H$ 184.4.

\section{Further Observations on the Voltaic Decomposition of Solutions. By Arthur Connell, Esq.*}

A FEW years ago I published a set of experiments on the A galvanic decomposition of solutions of binary combinations, such as acids or alkalies, in water and solvents containing water as a constitnent + ; and drew the general conclusion that in such cases the water of the solvent alone suffers the direct agency of the current. This rule of course did not include solutions of ordinary salts, in which the dissolved salt was admitted to be resolved into its constituent acid and alkali by direct voltaic action, at the same time that water was directly decomposed; but $I$ stated that when an aqueous solution of certain metallic salts, such as sulphate of copper, was made positive, and distilled water in a different vessel was made negative by a power of fifty pairs of two-inch plates, the connection being by asbestus, neither metal nor oxide was observed to be formed, whilst on reversal of the battery reduced metal immediately appeared on the negative foil now in the solution of the salt, in virtue, as $I$ conceived, of the reducing action of nascent hydrogen arising from decomposed water.

This experiment was perfectly accurate with reference to the circumstances under which it was made. About the same time Professor Daniell varied those circumstances so as to admit of a much more powerful voltaic agency, by using solution of potash instead of distilled water, and separating this

* Communieated by the Author.

+ Vol. xviii. of this Journal, S. 3. p. 241. It seems that it is not altogether superfluous to state, that I did not hold in the memoir referred to, as has been sometimes imagined, that water is the only compound body which is decomposed by electrical agency. I spoke of solutions only, whilst every body knows that Mr. Faraday has proved that many dry and fused oxides and haloid salts are decomposed by the galvanic current.

Phil. Mag. S. 3. Vol. 24. No. 158. March 1844. M 
solution from that of the metallic salt by an animal membrane only.

When in these circumstances the alkaline solution was made negative and the solution of sulphate of copper positive by twenty couples of a large constant battery, and a very energetic action was thus produced, the membrane was found in ten minutes to be coated with metallic copper, mixed with black oxide of copper and blue hydrated oxide. This experiment I have found to be perfectly correct, and have obtained the result with a power of thirty-six pairs of four-inch plates on Cruickshank's construction.

Shall we conclude then that the copper in such cases is a product of the direct action of the current? A little consideration will, I think, show that this conclusion does not follow so clearly or necessarily as may at first sight be supposed. On this view the copper is travelling towards the negative pole till it comes to the septum, in the pores of which it meets with oxygen travelling in the opposite direction, and proceeding from the other solution. A good deal of the copper combines with this oxygen and forms the oxide we find on the membrane, but a part of the metal does not succeed in effecting this union, and is deposited in the metallic state, the equivalent oxygen escaping. But can we not conceive, on the supposition that water is undergoing direct decomposition on both sides of the membrane, that the substance of that membrane may, in like manner, present an obstacle to the union of the hydrogen and oxygen travelling in opposite directions? and if any part of the hydrogen fails in effecting this combination, it will of course exercise a reducing action on the copper solution, just as it would do at the pole itself. Thus then it may be doubted whether the experiment affords any conclusive argument on either side. If neither metal nor oxide appeared at the septum, this would indeed be decisive against direct electrolysis of oxide or oxysulphion; but it may be doubted if the observed appearances are conclusive as establishing such direct decomposition.

A method occurred to me by which it might be possible to get some additional light on this subject. It soon became evident that the substance of the membranes is not the only obstacle to the combination, whether of copper or of hydrogen, with oxygen. The oxide of copper deposited on the septum plainly increases this obstacle, not only by penetrating into its pores, but by forming a layer on its surface; and on examining some of the membranes after experiment, I noticerl that the copper was chiefly deposited on the outer surface of such a layer of oxide. It therefore appeared that the best way to 
test the nature of the action would be to employ some solution which would yield a matter capable, by deposition in the substance of the membrane, of increasing the obstacle, and would likewise contain another matter which might be the subject of a secondary agency, if it really was hydrogen which experienced the difficulty in uniting with oxygen coming from the other sicle of the septum. The salt which appeared to me to offer these conditions was iodate of magnesia. If a solution of it were substituterl for sulphate of copper, then if magnesium were to be carried by direct agency towards the membrane, we should of course simply expect that, as in the case of sulphate of magnesia, a deposit of magnesia would take place on the diaphragm, the affinity of magnesium for oxygen being too strong to allow any of it to escape combination with the oxygen coming in the opposite direction. On the other hand, if water was the subject of direct decomposition, and if from the contemporaneous decomposition of iodate of magnesia into its constituent acid and alkaline earth and precipitation of magnesia on the septum, an obstacle should be offered to the whole of the hydrogen uniting with the whole of the oxygen passing in the opposite direction, we should expect that the portion of hydrogen escaping union would reduce iodic acid at the septum, as it does when it reaches the pole immersed in a solution of that acid or of one of its salts.

'The arrangement I employed for the experiment was very simple. A circular piece of bladder was cut rather larger than a watch-glass, and a segment of this circle, somewhat larger than the half, was moistened and made to adhere to a half of the hollow surface of the watch-glass, a portion of it being at the same time made to stand perpendicularly in the direction of the diameter of the circle, so as to form a septum across it, the remainder of the edge being bent over the outer edge of the watch-glass so as to adhere to it, and the whole being then allowed to dry. In this way, by pouring small quantities of two liquids on each side of the central diaphragm, they could be kept separate for a sufficient time to try voltaic action on them; it being found, however, that some fluids answered better to be placed on the bladder-side and others on the other division, so as to prevent subsequent mixing. When a dilute solution of potash was placed on the bladder-side of the septum and a solution of sulphate of copper on the other, and the former made negative and the latter positive by platinum wires from thirty-six pairs of four-inch plates, the side of the diaphragm towards the sulphate of copper was found in a quarter of an hour or twenty minutes to exhibit metallic copper lying on a dense layer of blue oxide of copper. 


\section{Mr. Connell on the Voltaic Decomposition of Solutions.}

A solution of iodate of magnesia, obtained by saturating solution of jodic acid with calcined magnesia with the aid of heat, was mixed with starch solution and placed on the bladder-side of the septum, and a starch solution on the other side of it; and the former made positive and the latter negative by thirty-six pairs of four-inch plates. In three or four minutes blue matter was observed beginning to be formed and soon increasing considerably, being deposited on the positive side of the diaphragm, and thence spreading into the liquid. None whatever appeared on the negative side. When examined after twenty minutes' action, the blue matter was found to be mixed with magnesia. I conclude, therefore, that the whole of the hydrogen arising from directly decomposed water did not succeed in uniting with the oxygen coming in the opposite direction from the other side of the diaphragm, and that the obstacle to this union gradually increased as magnesia continued to be drawn towards the diaphragm and to be deposited in its pores, and ultimately on its surface. 'This hydrogen so escaping combination united in its nascent state with the oxygen of iodic acid, and set the iodine free, producing the usual blue compound with starch.

The nature of the action was still further illustrated when solution of iodate of potash or of iodic acid was substituted for that of iodate of magnesia, all other circumstances being the same. With the first of these substances a mere trace of blue matter appeared on the positive side of the diaphragm in a quarter of an hour, and more on the other side; and with the second of them no blue was visible on either side in that time. The explanation seems to be that a trifling obstacle is afforded by the accumulation of a concentrated solution of potash in the pores of the diaphragm on its positive side, to the union of the hydrogen and oxygen passing in opposite directions, where iodate of potash is acted on; whilst where iodic acid is employed no substance is drawn towards the diaphragm, its pores suffer no obstruction; and no sufficient obstacle is afforded to the combination of hydrogen and oxygen so as to produce any secondary action.

Some observations which were made in a different quarter* on the experiments formerly detailed, will not occupy much time in noticing them.

I argued that such substances as iodic acid and bromide of iodine in solution were not directly decomposed, because when positively electrified in connexion with negatively electrified solution of starch, iodine did not pass towards the negative

* See observations of M. Poggendorff in the supplementary volume of his Annalen, p. 590. 
pole. On this it was observed, that the iodine would form iodic acid with the oxygen coming from the starch solution in the opposite direction, and so not appear in a free state. I answer, if so, why did not the iodine ultimately appear at the negative pole, and there affect the starch, seeing that the newly-formed iodic acid would be as liable to direct decomposition as the original? Again, if bromide of iodine was directly decomposed, why was there effervescence at the positive pole, and why was not an orange compound of bromine and starch formed at that pole?

Analogous views are applicable to the decomposition of the hydracids, and were formerly sufficiently explained*.

As to the observation on my argument for the solution of haloid salts as hydracid salts, that the acid and alkali formed in the circumstances mentioned + might have arisen from the union of the elements of the haloid with those of water, it is plain that this view assumes that haloid salts, supposing them to be dissolived as such, are directly decomposed by the current, whereas it was established by evidence of exactly the same kind, as in regard to hydracids, that the electro-negative element appearing during their decomposition has a secondary origin. But further, supposing this had not been established, on what grounds can we assume that if the haloid is dissolved as such, and directly decomposed, the hydracid supposed to be formed by the subsequent union of the electro-negative element with hydrogen shall not be equally directly deconuposed? and if so, how can we have any acid to detect, far less a constantly accumulating quantity of it?

St. Andrews, January 27, 1844.

XXVII. On the remarkable Fossil Trees lately discovered near St. Helen's. By E. W. Binney, Secretary of the Manchester Geological Society $\ddagger$.

DROBABLY no fossil plant has excited more discussion among botanists than the Stigmaria. It is the most common of the whole number of plants found in the coal measures, but there has hitherto been the greatest uncertainty as to its real nature. In the Lancashire coal-field traces of it may be found in every mine. It abounds in all the floors of the coals unmixed roith any other plants, and having the long stringy fibrils hitherto considered as leaves radiating from the stem in all directions, and often the fibrils alone are seen without

* See p. 246-7 of the memoir in this Journal above referred to.

+ See p. 357, \&c.

\# Communicated by the Author; having been read before the Manchester Geological Society, October 26, 1843. 